\title{
EEN IVOREN PANEELTJE MET EEN VOORSTELLING VAN EEN LIEFDESPAAR
}

Sinds oeroude tijden wordt in India ivoor toegepast op luxevoorwerpen. De olifant is er inheems, dus is ivoor voorhanden. Maar levende olifanten voorzien van hun eigen slagtanden, stonden in hoog aanzien en werden gebruikt bij het oorlogvoeren als tank in speciale brigades, en bij belegeringen als stormram; voor het vervoeren van zware lasten dienden ze als heftruck. In deze functies werden de olifanten bereden door een kornak, een speciaal hiervoor opgeleide bestuurder gezeten op de nek van de dikhuid met een speciale haak die op een plek op de kop werd gehouden als stuur. Het gebruik van een olifant als middel van vervoer was voorbehouden aan prinsen, koningen en keizers. Deze vorsten zaten dan in een speciaal olifantenhuisje op de rug van het dier. Maar ook dan functioneerden kornaks als chauffeur. Olifanten werden bereden bij de jacht op grootwild, zoals tijgers, leeuwen en neushoorns, en in staatsieoptochten.

Bij olifanten werd de aanwezigheid van hun slagtanden op prijs gesteld. Slagtanden van dode en dus meestal oude olifanten waren minder geschikt voor bewerking. Bovendien hebben niet alle Indische olifanten slagtanden. Mede daarom prefereerden de ivoorsnijders ivoor van de Afrikaanse olifant. Het gebruik van voorwerpen gemaakt van slagtanden van olifanten was net als de olifanten zelf, voorbehouden aan de hogere klassen. Het Rijksmuseum kon in 2004 een ivoren paneeltje met een voorstelling van een liefdespaar verwerven, dat zonder twijfel gebruikt werd in de hogere kringen van een stedelijke bevolking van middeleeuws India (afb. 1 en 2 ). ${ }^{1}$

Door ons paneeltje te vergelijken met twee ivoren paneeltjes op een tentoonstelling in het Los Angeles County Museum of Art die beide afkomstig zijn uit Orissa (een staat aan de noordoostkust van het Indisch subcontinent) en waarin eveneens een liefdespaar is uitgesneden ( $a f b .3$ en 4), ontstaat er meer inzicht in de plaats en tijd van vervaardiging. Ons paneeltje is eveneens in Orissa gemaakt en staat wat betreft datering tussen de twee paneeltjes uit Los Angeles in. Het staat echter dichter bij het vroegste exemplaar, waarin de vrouw zich verlegen afwendt onder de liefkozingen van de man (afb. 3) - een geheel andere situatie dan op ons paneeltje. Dit exemplaar is vroeger en dateert uit de $14^{\mathrm{e}}$ eeuw. Het tweede paneeltje (afb. 4) is veel later en dateert waarschijnlijk uit de $17^{\mathfrak{e}}$ eeuw. Ons paneeltje kan aan de $15^{\mathfrak{c}}$ eeuw worden toegeschreven. ${ }^{2}$

De voorstelling op het paneeltje van een man die een vrouw liefkoost op een bed, wijst op een functie in verband met de omgang van man en vrouw met elkaar, of ook op de daaraan voorafgaande handelingen zoals het baden, het verzorgen van het lichaam en het verfraaien van het uiterlijk. ${ }^{3} \mathrm{Er}$ is een klein aantal gebruiksvoorwerpen die hiervoor in aanmerking komen. Het zou het middendeel van een haarkam kunnen zijph, maar de aanzet van tanden aan 


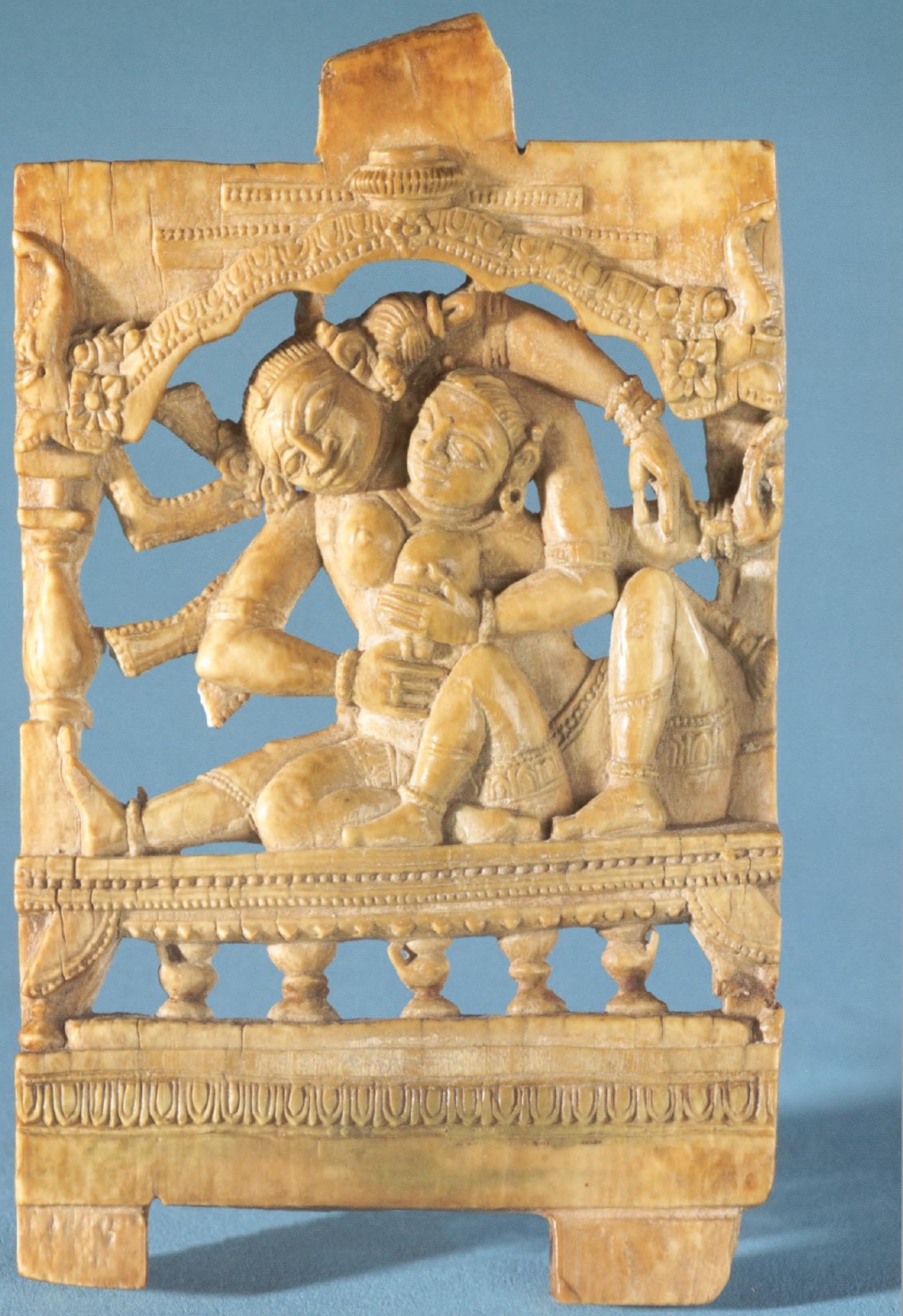




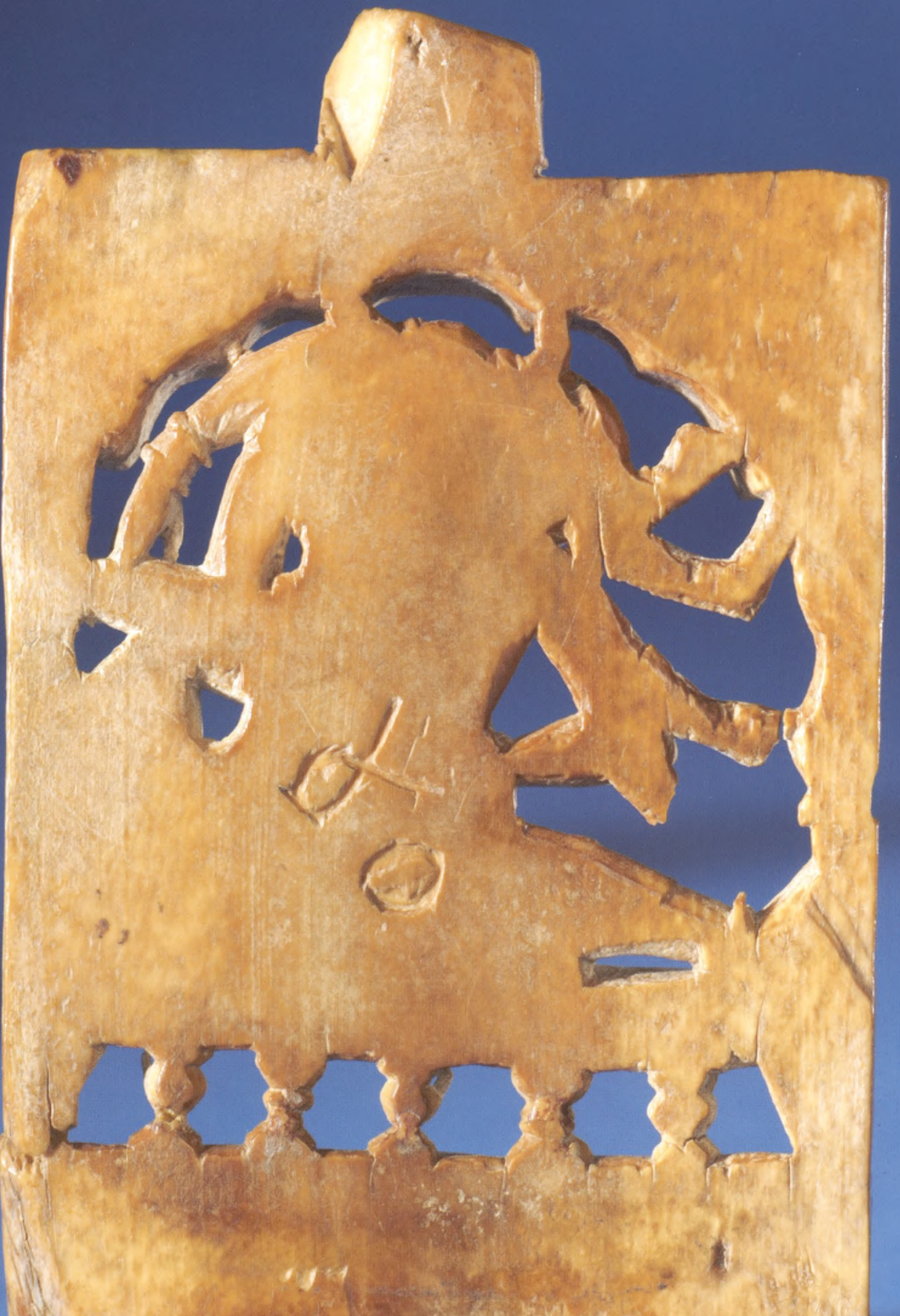

I 
onder- en bovenkant van het paneeltje ontbreekt. Het zou ook een onderdeel van de zijkant van een toilet- of juwelenkistje geweest kunnen zijn, maar voor fineer is het plaatje te dik en pennen of gleuven aan de zijkanten om de

\section{Afbeelding 2} Achterzijde paneel afb. 1 plaatjes aan elkaar te bevestigen, ontbreken. De twee pennen aan de onderkant, en de ene pen aan de bovenkant kunnen alleen maar bedoeld zijn om in gleuven van twee horizontale ivoren balken, één er boven en één er onder, te verdwijnen. Een reeks van dit soort ivoren paneeltjes naast elkaar tussen horizontale balken vormde de sierrand van een ledikant. De versiering van een liefdespaar wijst erop dat het niet in de eerste plaats diende om op te slapen. Het traditionele Indiase bed, charpoy, 'vierpoot', werd al bejubeld door de Afrikaanse reiziger Ibn Batuta, die omstreeks het midden van de $14^{\mathrm{c}}$ eeuw in India rondreisde. 'De ledikanten in India zijn erg licht. Een man kan er in zijn eentje één dragen, en elke reiziger zou zijn eigen ledikant moeten hebben dat zijn slaaf op zijn hoofd meedraagt. Het bed bestaat uit vier kegelvormige poten waarop vier balken worden gelegd; daartussen vlechten ze een soort koorden van zijde of katoen. Als je er op ligt, heb je verder niets nodig om het verend genoeg te maken. ${ }^{4}$ Ons fraai gedecoreerde paneeltje is echter geen onderdeel van een lichtgewicht veldbed, maar is afkomstig van een kostbaar slaapkamermeubel dat zeker niet bedoeld was om mee op reis te nemen. Het hemelbed maakte deel uit van een met zorg samengesteld interieur. Een dergelijk bed, voorzien van een baldakijn op gebeeldhouwde poten, is op het paneeltje zelf afgebeeld.

Het hemelbed op het ivoren paneeltje, en dus waarschijnlijk ook het hemelbed waarvan ons paneeltje oorspronkelijk deel uitmaakte, heeft een traditionele, Zuid-Indiase vorm, die ook aan zetels, tronen en voetstukken gegeven werd. Deze meubelen werden alleen gebruikt door hooggeplaatste personen en goden. ${ }^{5}$ Het bestaat uit een bodem, in het geval van een bed ongetwijfeld bestaande uit koorden die tussen een raam van vier stevige balken geregen zijn, net als bij het ideale veldbed door Ibn Batuta beschreven; in het geval van een zetel, troon of voetstuk werd een steviger bodem gebruikt, bijvoorbeeld van hout. De rand van ivoren paneeltjes was de sierrand daaromheen. De bodem staat op vier poten die de vorm hebben van leeuwenpoten, die hier niet helemaal uit de verf zijn gekomen. Op de vier hoeken verheffen zich zuilen, die het gebogen baldakijn dragen. Op de punten waar de zuilen het baldakijn raken zijn makara's, mythische waterdieren, aangebracht. De sierrand van het bed is hier vanwege het kleine formaat eenvoudig gehouden en bestaat slechts uit twee evenwijdige banden en een parelrand. Onder het bed staat een rij waterkannen.

De andere paneeltjes van onze bedrand waren waarschijnlijk ook uitgesneden met voorstellingen van een man en een vrouw al dan niet als paar, in verschillende stadia van toenadering. Hierbij werd een Ars Amandi gevolgd, zoals bijvoorbeeld de in het Westen overbekende Kama Sutra. Maar de Kama Sutra zelf zal het niet geweest zijn. Orissa, de streek waar deze beddenversiering gemaakt is, kent net als veel andere delen van het Indisch subcontinent, zijn eigen varianten en bewerkingen van deze oudste standaardtekst over dit onderwerp. Ook uit de klassieke Sanskrit-literatuur spreekt brede bekendheid met de inhoud van de Kama Sutra, zoals uit de twee passages hieronder zal blijken. De theorieën uit de Ars Amandi waren dus algemeen gedachtegoed in het Indisch subcontinent.

Dit soort encyclopedieën beschrijft alle facetten van de omgang van man en

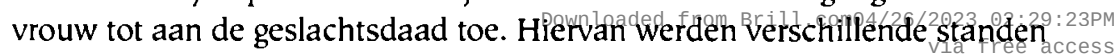



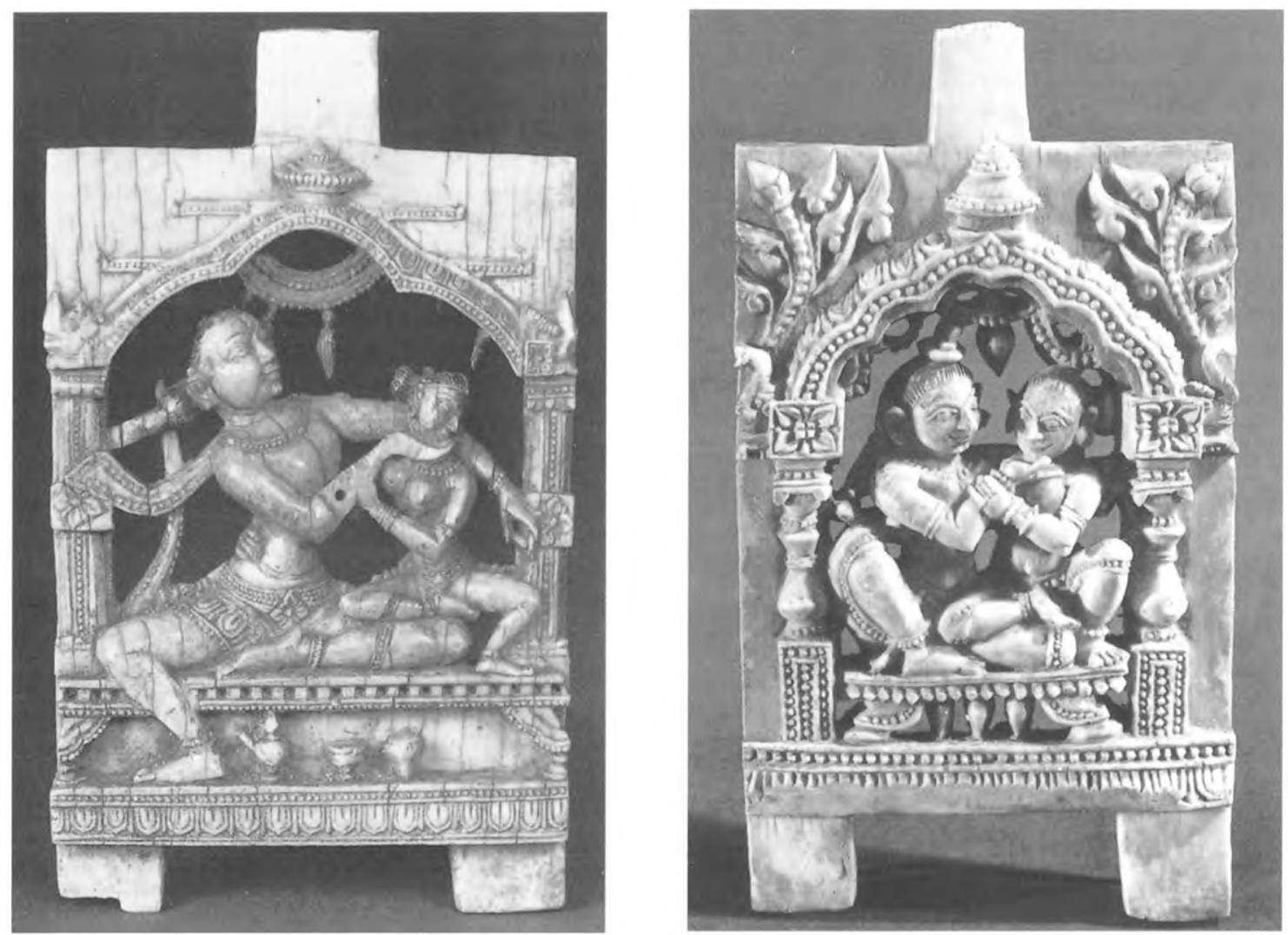

Afbeelding 3 (links) Liefdespaar, India, Orissa, $14^{\circ}$ eeuw

Afbeelding 4 Liefdespaar, India, Orissa, 17 eeuw gegeven, waaronder ook onrealistische, acrobatische standjes. Op de verder onbewerkte achterzijde van ons paneeltje staat een krabbel, waarschijnlijk het getal 40 . Ons paneeltje was dan nummer 40 in een reeks. Een complete serie bestond waarschijnlijk uit een aantal van vierenzestig. In het oude India had men een voorkeur voor getallen die door vier deelbaar zijn, soms met één, of juist twee, extra.

Diezelfde teksten die de omgang tussen man en vrouw behandelen, geven aanbevelingen voor de inrichting van de slaapkamer. Daarin wordt dan ook een comfortabel bed met een wit dekbed en donzen kussens genoemd. In de kamer staan verder een divan en een tafeltje met potjes en flesjes met zalven, poeders en parfums, op de grond een mand met bloemslingers die elke dag ververst worden. Ook zijn de benodigdheden voor het betelkauwen aanwezig, inclusief verse betelbladeren en een kwispedoor. Er staat een tafel om op te kunnen schilderen of tekenen, er zijn kastjes aan de muur voor boeken van palmblad, en er hangt een harp aan de muur. ${ }^{6}$ In een dergelijk interieur stond dus waarschijnlijk het hemelbed waarvan ons paneeltje een onderdeel was.

In de $7^{\mathbf{e}}$-eeuwse schelmenroman van Dandin, De Avonturen van de Tien Prinsen, komt een passage voor waarin een prins beschrijft hoe hij 's nachts in een paleis inbreekt en in een soortgelijk vertrek terecht komt. Daar ligt een wonderschone prinses in diepe slaap. Prompt vergaat hem de lust tort stellenecess 
want zij heeft onmiddellijk zijn hart gestolen. Aan de beschrijving van haar aantrekkelijkheden besteedt hij tien keer zoveel regels als aan haar bed, zodat enkele overeenkomstige details zoals de sierrand helaas ontbreken. Hier beperken we ons tot het bed: 'Bij het licht van met juwelen bezette lampen zag ik daar de prinses, te midden van haar gevolg, dat vermoeid door allerhande vermaak lag te slapen. $\mathrm{Zij}$ lag op een rustbank, waarvan de met grote, kostbare juwelen bezette ivoren poten de vorm hadden van rustende leeuwen en die bedekt was met een met ganzendons gevuld bed, rondom bestrooid met bloemblaadjes. ${ }^{7}$

Op het hemelbed op ons ivoren plaatje bevindt zich een verstrengeld liefdespaar. De man zit met het rechterbeen gestrekt en het linker opgetrokken en houdt de vrouw tussen zijn benen terwijl hij zich over haar heen buigt en haar bij het bovenlichaam beetpakt. Zij heeft haar armen naar achteren geworpen, alsof zij door de greep van de man overvallen werd. Toch zullen zij zich samen met duidelijke bedoelingen in dit liefdesnestje begeven hebben. In een ander Sanskrit werk, het epos De Dynastie van Rama door Kalidasa uit de $4^{\mathrm{e}}$ of $5^{\mathrm{e}}$ eeuw, komt een passage voor waarin de man de vrouw op een dergelijke manier verrast: 'Hij houdt er van haar te overvallen terwijl ze met welbehagen in de spiegel zit te kijken naar de afdrukken van zijn nagels in haar vlees veroorzaakt door zijn hartstochtelijke omhelzingen. ${ }^{8} \mathrm{Bij}$ ons paneeltje is de spiegel buiten beeld. Misschien was de vrouw met iets anders bezig. In ieder geval zijn de man en de vrouw op elkaar ingespeeld. De bedoeling van het kostbare en toepasselijk versierde hemelbed was om daarop als aangenaam tijdverdrijf, op volleerde wijze de liefde te bedrijven; met de eigen echtgenote, een bijvrouw, of een maîtresse die alle kneepjes van het vak kende. Deze maîtresses waren getalenteerde en goed opgeleide courtisanes verbonden aan een rijke beschermheer. $Z \mathrm{ij}$ maakten deel uit van de elitaire bevolkingsgroep in de grote steden van India. Ze werden getraind in de $64(4 \times 4 \times 4)$ kunsten, een verrassend gevarieerd pakket van kunsten en kennis, zoals de schone kunsten, farmacie, mineralogie, exploitatie van mijnen, magie, vermommingkunst, het bereiden van lekkere hapjes en sorbet, van cosmetica en parfums, het bedenken van charades en raadsels, om er enkele te noemen. Jongelingen uit de bemiddelde bovenlaag van de maatschappij, zonen van vorsten, ministers, rijke kooplieden, opgevoed in een kosmopolitische geest, gaven daar de toon aan. Ze leerden om te gaan met alle soorten vrouwen; van pril, onervaren en verlegen die de voorkeur verdienden als bruid, tot ouder, geraffineerd, opgeleid in deze 64 kunsten, die de ideale gezelschapsdames voor deze jongelingen van stand waren. ${ }^{9}$

Ons ivoren paneeltje is een plaatje uit een erotisch prentenboek ter opluistering van een belangrijke vorm van vrijetijdsbesteding van een jongeman uit een bevoorrechte klasse in het oude India.

\section{Noten}

* Met dank aan Dr. Herman Tieken, Universiteit Leiden

1. Verworven uit het M.J. Drabbe-fonds, ter beschikking gesteld door de ABN-AMRO. Inv. nr. AK-RAK-2004-1.

2. P. Pal, Elephant and Ivories in South Asia, Los Angeles, 1981, nrs. 75 en 76 . Met dank aan Stephen Markel, Curator and Bepartment Head South and Southeast 
Asian Art, Los Angeles County Museum of Art, die de collectie ivoren uit India in het LACMA aan een nieuw onderzoek heeft onderworpen en ons ivoor daarmee heeft vergeleken.

3. Voor sieraden gebruikt in een zelfde context in 18e-eeuws India, zie Pauline Lunsingh Scheurleer, 'Jewels for the Stadholder', in Susan Stronge (red.) The Jewels of India, Bombay, 1995, pp. 81-98. De sieraden zijn te zien in het CODA-museum te Apeldoorn.

4. Zie Henry Yule and A.C. Burnell, Hobson - Jobson, a glossary of colloquial AngloIndian words and phrases. New edition by William Crooke, New York, 1986, p. 185.

5. Zie bijvoorbeeld een beeld van een staande Vishnu in een $18 \mathrm{e}$-eeuws gekleurde tekening uit Orissa, in: Eberhard Fischer en Dinanath Pathy, Die Perlenkette dem Geliebten. Elf illustrierte Palmblätter zur Rasika Haravali-Romanze des Dichters Upendra Bhanja von Orisssa, Indien, Zürich, 1990, p. 21, onderste blad, rechts.

6. Zie Jeannine Auboyer, La Vie Quotidienne dans I'Inde Ancienne, Parijs, 1961, pp. 180-181.

7. Dandin, De Avonturen van de Tien Prinsen, Dasakumaracarita Schelmenroman. Uit het Sanskrit vertaald en ingeleid door Erik Maten, Amsterdam, 1981, p. 91.

8. Zie Auboyer, Op.cit. (noot 6), p. 299. Het nagenieten van de nagelafdrukken ontstaan tijdens hartstochtelijk liefdesspel is een clichébeeld dat eveneens uit de Kama Sutra afkomstig is. Nagelafdrukken zijn ook te zien op de linkerschouder van de Hemelse Schone uit Khajuraho in de collectie van de Vereniging, opgesteld in het CODA-museum te Apeldoorn, zie Pauline Lunsingh Scheurleer (red.), Asiatic Art in the Rijksmuseum, Amsterdam, Amsterdam, 1985, nr. 154.

9. Zie Auboyer, Op.cit. (noot 6) 